\title{
SIETE POEMAS DE CARLOS PELLICER
}

POR

\section{GABRIEL ZAID}

Carlos Pellicer nació en Villahermosa, cl 16 de encro de 1897 (aunque desde joven dijo que había nacido después: el 4 de noviembre de 1899, en la versión más difundida). Murió el 16 de febrero de 1976, en la ciudad de México, donde vivió desde niño. Su padre, farmacéutico, cmigró a la capital y compró una farmacia en 1908, que abandonó para tomar las armas constitucionalistas en 1913 (llegó a ser coroncl, y continuó despućs en cl cjército, como profesionista). Estudió con los jesuitas (becado, porque la familia tardó cn superar la estrechez cconómica) y en lit Escucla Nacional Preparatoria, decisiva para incorporarse a la gente de libros que pronto ascendería con la revolución triunfante. Compartió cl optimismo cristiano de sus maestros de la gencración del Atenco, y especialmente cl impulso creador y abicrto al mundo de José Vasconcelos, de quien fue secretario. Pudicra ser llamado un pocta de la Revolución (con López Velarde, Reyes, Gutiérrez Cruz, Leduc, Maples Arce), así como se habla de "novelistas de la Revolución."

Entre sus primcros pocmas (que prefirió no publicar), $\mathrm{cl} \mathrm{de} \mathrm{fecha} \mathrm{más} \mathrm{antigua}$ (17 de octubre de 1912) es un poema del paisaje (recogido por Luis Mario Schneider en las Obras. Poesía, Fondo de Cultura Económica, 1981):

La tarde iba a morir. Sobre las olas, el Sol una mirada postrera envió; cerró los párpados ... ya sus corolas de luz abrían los asiros cuando murió.

Aunque Pellicer llegó a molestarse de que lo redujeran a cso, deslumbró como paisajista desde su primer libro: Colores en el mar y otros poemas (1921). Es un libro todavía modernista, con notables pocmas de vanguardia, gracias a otro encuentro decisivo. Como líder estudiantil, fuc becado a Bogotá y Caracas (19181920) por la Federación de Estudiantes Mexicanos, para auspiciar la formación de federaciones semcjantes, que se integraran a una confederación. Pero, precisa- 
mente en csos años y en csas ciudades, cstaba José Juan Tablada, en el scrvicio diplomático y en su momento más creador: cuando aclimata el jaicú en nuestra Icngua y lanza la poesía vanguardista de Li-Po y otros Poemas (Caracas, 1920). Gracias a Tablada, Pellicer se cncontró a sí mismo como continuador de la tradición del paisaje cn la pocsía mexicana, aunque de una manera escandalosa para los fieles de esa tradición, que se remonta al siglo XVI. La poesía mexicana y cl paisaje quedaron irreconocibles.

Quizá la mejor manera de observarlo es leyendo estos siete poemas, cscritos entre 1919 y 1925. Consabidos, citados, antologados, tienen todavía qué decir.

\section{UN REPORTAJE IRONICO}

\section{RECUERDOS DE IZA}

(Un pucblecito de los Andes)

1 Crecríasc que la población, después de recorrer el valle, perdió la razón y se trazó una sola calle.

$2 \quad Y$ así bajo la cordillera se apostó febrilmente como la primavera.

3 En sus ventas cl alcohol está mezclado con sol.

$4 \quad$ Sus mujeres y sus flores hablan el dialecto de los colores.

$5 \mathrm{Y}$ cl riachuclo que corre como un caballo, arrastra las gallinas en febrero y en mayo.

6 Pasan por la acera lo mismo cl cura, que la vaca y que la luz postrera.

$7 \quad$ Aquí no suceden cosas de mayor trascendencia que las rosas.

8 Como amenaza lluvia, se ha vuelto morena la tarde que era rubia. 
9 Parece que la brisa

estrena un perfume y un nuevo giro.

10 Un cantar me despliega una sonrisa y me hunde un suspiro.

Este pocma de 1919 forma parte de una seric (Recucrdos de los Andes), incluida en Colores en el mar con cl siguiente epígrafe: "Tres aguafuertes sobre la tempestad en los Andes, escritas en Boyacá, Colombia. Sobre esas montañas pasó y triunfó Bolívar en 1819, cl más gencroso de los hombres y cl más grande de los héroes." Es cl primero de sus homenajes a Bolivar, de quicn sicmpre fuc devoto. La scric anticipa el Canto general de Neruda, sobre todo en cl primer poema ("La tempestad en los Andes"), por una mirada épica que funde el paisaje y la historia, y que se mueve como un lente de gran angular. Esto se imitó mucho cn la llamada poesía tchírica, que desapareció, tal vez porque llegaron las superproducciones cinematográficas.

Aunque a Pellicer le gustaba haberse anticipado a Neruda, cl anteccsor último (en nuestra lengua) de esta vivencia nueva del paisaje (que funde la historia en la naturaleza como una presencia imponente que rebasa al yo) fue nuestro primer pocta romántico, José María Hercdia, que en 1820, a los 17 años, cscribe "En cl Tcocalli de Cholula". Heredia, nacido en Cuba, fue, como Pellicer y Neruda, viajero continental y antiimperialista.

Pero la scric vale más como lestimonio que como poesía, excepto en este poema nada épico ni romántico; más bien modernista, con tintes de vanguardia sobre todo por su fragmentarismo (scñalado con números) y la acumulación de imágenes. Pellicer se dio cuenta de que en este poema le había pasado algo importante. Sicmpre estuvo orgulloso del fragmento 7 , como de una hazaña juvenil, su primer hallazgo poćlico:

Aquí no suceden cosas

de mayor trascendencia que las rosas.

Las rosas modernistas dejan aqui de scrlo. Con una especie de agresividad cariñosa, muy mexicana y muy moderna (pero nada modernista), las rosas sufren un vejamen de la vanguardia: se vuclven cosas, entre tantas que pasan. La metáfora milenaria de la caducidad de las flores se trasmuta por una inversión. En vez de scñalar positivamente la vida de las rosas frente a la muerte que las degrada, la mekáfora pelliccriana degrada las rosas y, así, las aviva. 
Las palabras rimadas cosas/rosas subrayan el paralclismo degradante. Rcducen las rosas a cosas sin color, forma ni perfume. A sucesos sin importancia, que nunca saldrán en los periódicos. Negatividad que sirve, naturalmente, para ver lo contrario: las rosas como noticia, como el acontecer que realmente importa. Alguna vez dijo Chesterton que las cosas realmente importantes son las que no salen en los periódicos: por ejemplo, el milagro del amanecer. Algo así dicen estas líncas de reporlaje irónico: nada más importante que las rosas. Pero lo dicen con un giro que parece decir lo contrario: lo que está sucediendo es la noticia del siglo, pero, fucra de cse milagro, aquí no pasa nada.

Esta vivencia del paisaje es una crítica de la historia y del yo romántico, incapaz de ironía, solemnemente identificado con las fucrzas telúricas y sociales. Es una nucva forma de fusión, a través de la conciencia de la distancia, análoga al refinamiento popular del usted cariñoso: hablarle de usted a una persona querida, para acariciar la distancia, como una nueva forma de tuteo. Con razón dijo Octavio Paz que la pocsía de Pellicer inicia un nuevo diálogo con la naturaleza.

\section{AL TU POR TU CON LAS VANGUARDIAS}

\section{ESTUDIO}

Jugaré con las casas de Curazao, pondré el mar a la izquierda y haré más puentes movedizos. ¡Lo que diga el poeta! Estamos en Holanda y en América y es una isla de juguetería, con decretos de reina y ventanas y puertas de alegría. Con las cuerdas de la lira y los pañuelos del viaje. haremos velas para los botes que no van a ninguna parte.

La casa de gobierno es demasiado pequeña para una familia holandesa.

Por la tarde vendrá Claude Monet a comer cosas azules y cléctricas. Y por esa callejuela sospechosa haremos pasar la Ronda de Rembrandt. ... pásame el pucrto de Curazao! isla de juguetería, 
con decretos de reina

y ventanas y puertas de alegría.

Fechado en Curazao 1920, publicado en Colores en el mar (1921), recogido por José D. Frías en su Antología de jóvenes poetas mexicanos (París, 1922). Es decir: a los 23, 24 y 25 años del joven Pellicer que, con este poema, se pone al tú por tú con las vanguardias del momento. Hay que ver lo que se escribía en Europa hacia 1920. ¿De dónde sale csta libertad prodigiosa? No de sus pocos años. Muy raramente es cierto que los jóvenes hagan poesía nueva, como este poema, que sigue siendo joven, a diferencia de muchos poemas de vanguardia escritos por cntonces.

Es una libertad que viene de Bogotá, donde estuvo de octubre de 1918 a marzo de 1920, cuando pasa a Caracas (seguramente en barco, por Curazao). Por esas fechas, el segundo secretario de las legaciones mexicanas en Colombia y Venezucla cra nada menos que José Juan Tablada. Y cra cl mcjor Tablada: cuandio salta del modernismo a la vanguardia. Fue precisamente en Caracas y por entonces cuando Tablada publicó Un día ...Poemas sintéticos (1918) y Li-Po yotros poemas (1920).

Hay un salto paralclo de Pellicer, siguiendo a Tablada. Hasta 1919, cl joven Pellicer cra un pocta fósil, seguidor de los modernistas, como puede verse en los pocmas que nunca publicó. El pocta juvenil era Tablada, cuya singularidad: un pocta que se vuclve dos generaciones poéticas, quizá marcó a Pellicer, que no parece haber sentido la necesidad de romper con el modernismo, tal vez porque llegó a la vanguardia siguiendo a un modernista.

Este pocma puede considerarse creacionista. Pero lo que en Huidobro es programa (¿Por qué cantáis la rosa, oh poctas? „Illacedla florecer en el pocma! ... El pocta es un pequeño Dios) aquí cs realización. El pocta, como un pequeño Dios, hace lo que se le pega la gana con la isla de Curazao: pone cl mar a la izquierda, mueve puentes, juega con las casas, convierte las callcjuclas sospechosas en escenario cinematográfico de La Ronda de Rembrandt, hace venir a Claude Monet a comcr cosas azules y cléctricas.

La solución genial que es la palabra cosas. No es cl nombre de nada. Es una palabra comodín que puede sustituir cualquicr nombre. Por eso sucle cmpobrecer. $Y$ aquí, por cl contrario, sorprende como recurso enriquecedor, que sirve para nombrar una realidad sin nombre. El lector puede pensar, si quicre, en algo así como ciruclas relampagucantes de azul. Puede pensar en un atardecer impresionista: en colores que se desprenden de la realidad y flotan como puntos o manchas o nenúfares de Monct. Pero cl impresionismo aquí no es simplemente una alusión, como para decir: lo que estoy viendo parece un cuadro de Monet. Se vuclve 
impresionismo litcrario: una mancra poética de pintar con palabras tan vagas como manchas que azulean, como nombres desprendidos de la realidad. La palabra cosas, tan vaga que no sucle servir para nada, sirve aquí para pintar con cxactitud.

(En 1929, José María González đe Mendoza señaló la importancia de esta palabra en Pellicer. Cuestión que daria para hacer una tesis, pero que sigue, como todo Pellicer, sin estudiarse).

El creacionismo del pocma también es operante, más que alusivo. Ni siquicra sabemos si Pellicer sabía cntonces del creacionismo. Donde Huidobro lo propone (¿Por qué cantáis la rosa, oh poetas? „llacedla florecer en el poema!) se limita a cantar la libertad creadora. Pellicer la hace florecer en el poema. Por eso la libertad de este poema juvenil resulta contagiosa: no se puede pasar por la cxperiencia de lccrlo sin salir renovado, alegre, con otros ojos.

\section{NO DESEARAS LA POESIA DE TU PROJIMO}

\section{DESEOS}

Trópico, para qué me diste las manos llenas de color. Todo lo que yo toque se llenará de sol.

En las tardes sutiles de otras tierras pasaré con mis ruidos de vidrio tornasol. Déjame un solo instante dejar de ser grito y color. Déjame un solo instante cambiar de clima el corazón, beber la penumbra de una cosa desierta, inclinarme en silencio sobre un remoto balcón, ahondarme en el manto de pliegues finos, dispersarme en la orilla de una suave devoción, acariciar dulcemente las cabelleras lacias y escribir con un lápiz muy fino mi meditación. ¡Oh, dejar de ser un sólo instante el Ayudante de Campo del Sol! ¡Trópico, para qué me diste las manos llenas de color!

Publicado en Seis, siete poemas (1924), cs el pocma más antologado de Pellicer. Quizá llegó a odiarlo, porque a partir de cste pocma fue clasificado para 
sicmpre como pocta del trópico, del paisaje y del color. Lo más logrado del pocma es la parte contradictoria: cl pocta va diciendo todo lo que no es capaz de hacer, pero tan maravillosamente que se contradice. Es como si dijera: "yo nunca podré ser un López Velarde", pero igualando a López Velarde en el mismo acto. Quizá por esta igualación, no se ha visto lo que parece una alusión muy clara a López Velarde desde "cambiar de clima cl corazón" hasta "escribir con lápiz muy fino mi meditación". No hay que olvidar que por aquellos años los iemas y cl estilo de López Velarde tuvicron mucha resonancia, a partir de su muerie repentina y de la consagración póstuma que le dicron los revolucionarios en el poder. Pero en esie poema Pellicer no suena a López Velarde: hace presentes sus icmas sin recurrir a su cstilo. Esta alusión que nicga, asume, supera, respeta y se distancia del camino de López Vclarde, no ha sido lcída; sino cl declararse condenado a seguir su propio camino cxtcriorista.

Desgraciadamente, los pocmas que se prestan a ser leídos como declaraciones dejan de ser leídos como poemas. Pcro la poćtica explícita ("Todo lo que yo toque se llenará de sol") tiene menos interés poético que la efectuada magistralmente sin declaración alguna. Por cjemplo: la imagen de "beber la penumbra de una cosa desierla" recuerda a López Velarde de una mancra indefinida. Pudicra ser en rclación con cl poema titulado "En las tinicblas húmedas":

He aquí que en la impensada tiniebla de la muda ciudad, cres un lampo ante las fauces lóbregas de mi apetito; he aquí que en la húmeda tiniebla de la lluvia ...

... y sucnan tus palabras remotas

dentro de mí, con esa intensidad quimérica

de un reloj descompuesto que da horas y horas

en una camara destartalada ...

$Y$, sin embargo, "beber la penumbra de una cosa desierta" es una imagen tan pelliceriana que parcec la versión cn blanco y negro de

Por la tarde vendrá Claude Monet

a comer cosas azules y eléctricas.

El tema lopezvelardiano, asumido y negado como desco, se vuclve un tema pelliceriano en cl mismo acto de haccrlo presentc. Efraín Hucrta dejó cscrito: "No descarás la pocsía de tu prójimo". A esto se refieren los "Descos" del título del pocma. No son descos de sol, de color, de paisaje, tampoco de penumbra; son 
descos de otros temas, de otros poemas, de otras maneras de escribir. Parece un poema del trópico: es un poema del pocma imposible. La exaltación lopezvelardiana del desco carnal irrealizable se vuclve aquí sublimación pelliceriana del desco de una pocsía prohibida para un "ayudante de campo del sol".

\title{
IV. UN POETA AVIADOR
}

\section{SUITE BRASILERA, POEMAS AEREOS}

\section{PRIMERA VEZ}

\author{
Desde el avión, \\ vi hacer piructas a Río de Janciro \\ arriesgando el porvenir de sus puestas de sol. \\ Se ponía de cabeza \\ sin derramar su bahía. \\ Y en la lotería de sus isletas \\ ganaba y perdía. \\ El cielo se llenaba de automóviles \\ y de sombra a las 12 del día. \\ El Pão de Açúcar cra un espantapájaros \\ soberbio, de lógica y fantasía. \\ Las palmeras desnudas \\ andaban de compras por la Rúa D'Ouvidor. \\ De pronto la ciudad \\ entró en espiral \\ junto con el avión, \\ lo mismo que 300 kilates de diamantes \\ en el embudo de un buen corazón.
Al bajar, tenía yo los ojos azules y agua de mar dentro del corazón.

En México se han discñado y producido aviones desde 1915. En México se inventó cl correo aćreo: el primer envío mundial de cartas por avión fue de México a Pachuca, cl 6 de julio de 1917. Que esto lo ignoren los teóricos dependientes de las tcorías de la dependencia es su problema, no el de Pellicer. El avión, los automóvilcs, en este pocma, son tcmatización propia de una expcriencia propia; no menciones de moda, no simples ecos de Marinetti, que en 1909 abogó por un arte que fucra tan revolucionario y destructor del pasado, como la nucva tecnología. Pellicer ccicbra aqui el Nucvo Mundo de la máquina como celcbra el Nuevo 
Mundo brasilcño: en su propia experiencia, como un nucvo mundo "dentro del corazón". La aparición de las måquinas no es mecánica; la aparición de Río de Janciro no es turística. No es un poema datado, como tantos que hoy tienen el interés de una fotografía de la ćpoca, de una vicja postal. Recuerda más bicn esos poemas de Apollinaire donde lo nucvo sigue sicndo nucvo porque está integrado con lo vicjo; en este caso, la rima. Lo cual no opera por moderación: es un recurso técnico que permite comunicar la experiencia del salto jubiloso al nuevo mundo. Lo nucvo, lo que siguc aquí vivo, es la experiencia aérea vivida como experiencia creadora, desde adentro. Unos años después, Saint-Exupéry reinventa algo parecido en sus novclas, que llamaron la atención precisamente por loque tiene este pocma: la conquista poćtica deí cspacio aćrco.

En su "Oda a Salvador Novo", un pocma menos logrado que éste (porque, sin llegar a ser mecánico, procede por acumulación de menciones y programas "futuristas"), Pcllicer llama a Novo "pocta chofer". (La palabra "chofer" está datada: quería decir piloto deportista de automóviles, no criado; tenía la connotación de aventurero en las fronteras de lo posible, que hoy tiene todavía un conductor de coches de carrera y no un conductor de pasajeros). Si Novo hubicra escrito una "Oda a Carlos Pellicer" semejante, hubiera tenido que llamarlo "pocta aviador".

"Carlos Pellicer tuvo la pasión del vuclo. Desde niño, esta pasión lo hizo construir aviones y dirigibles con popotes de tela y cera, copias notables de los modelos originales, que cran la admiración de sus compañeros. En su juventud pensó scriamente en estudiar en una escuela de aviación. Conoció y voló con pilotos famosos - como lo prucban los artículos que aquí se publican-y todavía en 1926, cuando viajó a París, ienia la esperanza de ser admitido en una escucla de aviación -Alfonso Reyes hizo las gestiones necesarias-; pero cl elevado costo de los cstudios impidió definitivamente cl proyecto. Sin cmbargo, nunca abandonó el gusto por cl vuclo, y la noche del 21 de mayo de 1927, fue una de las sicte personas que ayudaron a Lindbergh a empujar el Spirit of St. Louis hasta un hangar en cl campo aćrco de Le Bourget, despućs del histórico vuclo. El pocta recordaría sicmpre la doble hazaña: la de Lindbergh y la suya, que le costó la pérdida de una manga del saco y de un zapato".

Los poemas aćreos llevan por título "Primera vez", "Scgunda vez", ctc. Esto (no hay que olvidar que se trata de aviación deportiva) alude a prácticas de vuclo. El pocma "Primera vez" se desplicga como un tonneau: una cspiral de barril. La scric forma parte del libro Piedra de sacrificios. Poema iberoamericano, publi-

\footnotetext{
'Carlos Pcllicer, "Dos textos inéditos" presentados por Carlos Pellicer López, Revista de la Universidad, X-XI 80, pp. 18-22.
} 
cado en 1924, con prólogo de José Vasconcelos y un dibujo de Adolfo Best Maugard ("Guanabara"), que también se despliega como un tonneau: es una vista aćrea de las casas de Río y los barcos de la bahía girando en espiral hasta formar un pan de azúcar. La seric está dedicada (en la edición original) a Francisco $\mathrm{S}$. Espejel y Julián Navas Salinas, aviadores muertos en accidentes aćreos en 1923.

En 1922, Brasil celebró el centenario de su independencia. México envió una delegación encabezada por el secretario đe educación, José Vasconcelos, que llevó cn su comitiva a Pedro Henríquez Ureña y otras personalidades, al joven Pellicer y a los pilotos mencionados. Llevó también una réplica de la estatua de Cuauhtémoc que cstá en Insurgentes y Reforma. Pellicer acompañó a los pilotos cn algunas exhibiciones sobre Río. En particular, como copiloto y único acompañante de Espcjcl, en un looping arriesgadísimo, con mal tiempo y a muy baja altura, dcjó cacr flores sobre la estatua y sobre una multitud que se temió lo peor, cncabezada por el presidente de Brasil, Vasconcelos y cl cuerpo diplomático. Naturalmente, en vez đe cosechar aplausos, cosechó cl enojo de Vasconcelos (aunque no el arresto, como Espejcl). Cosechó también los poemas aćreos de la "Suitc brasilera" y cl aura de pocta futurista y revolucionario².

Habría que cstudiar este lado Mayakoski, Malraux, Hemingway, de Pellicer, cuando la Revolución era todavía la Revolución. Así como su padre tomó las armas con Carranza, Pellicer tomaba alas futuristas con la aviación del gobierno revolucionario.

En el prólogo del libro, dice Vasconcelos: "Desde la nave aérea ha visto Pellicer su América (...) Leyendo estos versos he pensado en una religión nueva que alguna vez soñé predicar: la religión del paisaje (...) El alma y cl mundo fundidos y como recién creados $\mathrm{en}$ el seno de una potencia que supera la realidad ordinaria. (...) Pellicer, como buen místico, crea sus paisajes". Y, en el primcro de los dos artículos de 1923 exhumados por su sobrino, dice Pellicer:

"Estos pocmas no deben sorprender a nadie, si se piensa que han sido escritos con la lógica de los aviadores. El aviador, desde su avión, está haciendo cl mundo a su antojo. Con medio looping pucde mover el lugar de las cosas y con un tonneau consigue fácilmente retorcer el paisaje. La de los aviadores en una lógica dinámica que no tiene nada que ver con la del resto de los hombres. Cuando cl piloto cs muy hábil para cjecutar actos de acrobacia, se tiene la impresión real de que no es $\mathrm{el}$ avión, sino las cosas las que se mueven. El aviador antes que otra cosa es artisla. Podrá tener ciencia profunda en motores, estabilidad, ctc., pero el acto de volar es ya en sí un acto de belleza. Esto, naturalmente, no lo sabe la mayoría de los

\footnotetext{
2 Senén Mexic, "Pellicer y Vasconcelos en Brasil", transcripción de una conversación con Pellicer, Diorama de la Cultura, suplemento de Excélsior, 28 II 82, p. 10.
} 
aviadores. Así, son grandes artistas por la salvaje y magnífica espontaneidad. (...) Volar es el arte que cncierra en sí todas las artes y economiza la tarea desagradable de extcriorizarlos. El secreto de toda aptitud consiste en mirar las cosas desde el punto más alto. Cuanto mås alto $\mathrm{cs} \mathrm{cl}$ lugar, mayor es la aptitud para descubrir y gozar, y mayor también cl desintcrés, pues se llega al egoísmo espléndido de ser cl único y su propicdad. Allá arriba no le importa a uno nada. Nada se recucrda, nada se desea. Si acaso en ese aturdimiento divino se percibe de cuando en cuando cl desco único de no volver a ticrra jamás. La mucrte de Icaro, cl gran aviador gricgo de hace 10,000 años, se debió, sin duda a ese desco saludable y fatal de volar siempre, de no regresar nunca"s.

Llama la atención la clara conciencia en prosa de lo que cl pocta hizo en verso. La frase "haciendo el mundo a su antojo", que parece creacionista. La alusión al anarquista Stirner, autor de El único y su propiedad (alusión que se repite en la "Oda a Salvador Novo"). La anticipación que hay en todo csto del libro de sonctos rcligiosos titulado Práctica de vuelo y de su entusiasmo por los paisajes de José María Velasco: otro "místico" de la luz natural, de los grandes espacios, de "las cosas desde el punto más alto", de "la religión del paisaje".

\section{TROPICO ENGAÑOSO}

\section{ESTUDIO}

La sandía pintada de prisa
contaba siempre
los escandalosos amaneceres
de mi scñora
la aurora.
Las piñas saludaban el medio día.
Y la sed de grito amarillo
se endulzaba en doradas melodías.
Las uvas eran gotas enormes
de una tinta esencial,
y en la penumbra de los vinos bíblicos
crecía suavemente su tacto de cristal.
¿Estamos tan contentas de ser así?
dijeron las peras frías y cinceladas.

${ }^{3}$ Carlos Pellicer, "Dos textos inéditos" presentados por Carlos Pellicer López, Revista de la Universidad, X-XI 80, pp. 18-22. 


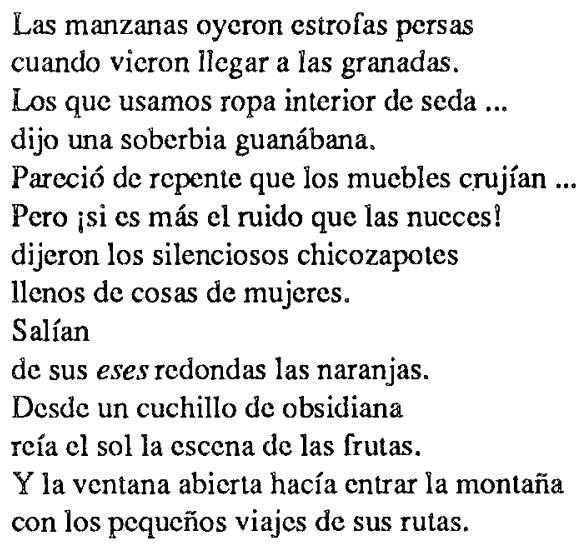

Frutas sin sabor, frutas sin olor. ¿No se supone que Pellicer es tropical? ¿Por qué un poema tan despicrto al tacto de las uvas, cl crujir de las nucces, cl color de la piña, no se lleva las frutas a la boca, no las hucle?

Así son los prejuicios. Ya se olvidó la acusación contra el joven poeta: no hacía poemas sentimentales, cra frío. Priva ahora el prejuicio contrario: frente a los fríos, Pellicer es tropical. Pero la calidez de este poema no es tropical: es coloquial. Como los bodegones, se mete a la cocina, escucha cl habla de las cosas vulgarcs, hace viva una naturalcza mucrta.

Porque de cso se trata: la naturalcza viva está afucra, en la montaña, invitándonos a salir. También cl sol cstå fucra, como un espectador condescendicnte que se asoma al interior. La ventana cs como la boca de un escenario, $\mathrm{cl}$ cristal de una vitrina de musco, el marco de un cuadro. Anacrónicamente, nos estorba Walt Disney, cuya obra es posterior. Pero el humor benćvolo, la cscenificación de frutas que entran y salen como personajes, cl color, la música, recucrdan sus dibujos animados.

También hay algo de bodegón: las peras frías y cinceladas, cl tacto de cristal que se traslada de la redondez de las copas a la plenitud creciente de las uvas, esa penumbra de los vinos bíblicos que cambia todo el escenario y confirma la lectura de Cucsta: "Es maravilloso cómo Pellicer decepciona a nuestro paisaje". Si una palabra basta para sacar del trópico cste pocma, que habla de piñas y guanábanas, es la palabra bíblicos. Y qué adjetivo inusitado y cxacto: aliteración y rima de vinos, cierre perfecto del endecasílabo, connotación de antigücdad, buena cepa, nobleza, añcjamiento; asociación con la penumbra de muchos cuadros bíblicos. Pudo habcr dicho, simplementc: en la penumbra de los vinos añejos y hubicra dicho menos. 
Hay, finalmente, una acuarcla pintada de prisa. Laacuarela cs pintura de agua; hay que terminar antes de que seque. La sandía es aguada también, y tiene algo de csquemático, de haber salido del taller de Dios a la carrera, en pocos trazos. Esta velocidad creadora la tiene el Estudio: va retratando con unos cuantos rasgos, pasa de un personaje al siguientc. Arranca con brio desde el primer verso, que no sólo se reficre a la prisa sino que la demucstra andando apresuradamente:

\section{Lasan-díapin tádade prísa}

Se trata de un decasílabo dactílico, verso de diez sílabas con acento en la tercera, sexta y novena, que tiene aire de marcha y que es común en himnos nacionales:

\section{Mexicános, al gríto de guérra, La sandía pintáda de prísa}

Pero pintada de prisa tiene un paso mâs vivo que al grito de guerra, a pesar de las analogías prosódicas entre ambas frascs. Hay una diferencia. Las sílabas gril gue, que llevan la aliteración en g, llevan también los acentos del verso, y por lo mismo se pronuncian mås lentamente, como sílabas largas. Esta coincidencia de dos subrayados prosódicos (que puede extenderse a la sílaba ca, casi aliteración de gue) sucna machacona y solcmnc: un aire de marcha pero lento, con acentos y alitcraciones en las sílabas 3/6/9. En cambio, la alitcración pin/pri no va a compås con la marcha de los acentos. La alitcración está en las sílabas 5/9, los acentos cn 6/9. La sílaba pin cs átona, breve y vcloz. La sílaba pri, aunque más larga, no se alarga tanto como gue, aunque (como gue) llcva el acento final del verso. Esto se debe a la última sílaba: pri se dice más aprisa en prisa que en pria, por cjemplo, o (si qucremos decepcionar de otra mancra a nuestro paisaje) en PRI:

\section{Mexicanos, al grito de guerra, \\ La sandía pintada de PRI}

La $i$ larguísima de sandía contrasta con la brevedad de las íes de pintada y de prisa. La segunda, en particular, va fuera de paso con la acentuación y parece hacer ese movimiento rapidísimo de los pies con que volvemos a tomar el paso en una marcha. Todo lo cual sirve para que la prisa se mucstre andando en este verso y haga así coincidir la exactitud metafórica (la sandía cs como una acuarcla pintada de prisa) con la velocidad prosódica.

No, no cstamos en cl trópico. Estamos en cl estudio de un artista. La metáfora central del pocma es que las frutas son como obras de arte. Como pintura (la 
sandía), escultura (pcras cinceladas), cristalería (uvas gotas de tinta), ebanistería (nucces), Iencería (guanábana), papel recortado (naranjas). Como silencio o como música (chicozapotes, nueces, granadas, piñas).

\section{CRITICA DEL RELOJ}

\section{ESTUDIOS}

\section{$\mathbb{I}$}

Relojes descompuestos, voluntarios caminos

sobre la música del tiempo.

Hora y veinte.

Gracias a vucstro

paso

Iento,

llegó a las citas mucho después

y así me doy todo a las máquinas

gigantescas y translúcidas del silencio.

\section{II}

Diez kilómetros sobre la vía

de un tren retrasado.

El paisaje crece

dividido de telegramas.

Las noticias van a tener tiempo

de cambiar de camisa.

La juventud sc prolonga dicz minutos,

cl ojo caza tres sonrisas.

Kilo de panoramas

pagado con el tiempo

que se gana perdiendo.

III

Las horas se adelgazan;

de una salen diez.

Es el trópico,

prodigioso y funesto,

Nadic sabe qué hora es. 
No hay ticmpo para cli tiempo.

La sed es labia cantadora

sobre ese oasis enorme,

deslumbrante y desierto.

Sueño. Desnudez. Aguas sensuales.

Las ccibas se estilizan. Nacen tres mil cedros.

Algo ocurre: que hay un árbol demasiado joven

para figurar en un paisaje

tan importante.

Tristeza.

Siempre grande, noble y nueva.

Los relojes se atrasan,

se perfecciona la pereza.

Las palmeras son primas de los sauces.

El caimán es un perro aplastado.

Las garzas inmovilizan el ticmpo.

El sol madura entre los cuernos

del venado.

La serpiente

se suma veinte veces.

La tarde es un amanecer nuevo y más largo.

En una barca de caoba,

desnudo y negro,

baja por el río Quctzalcóatl.

Lleva su cuademo de épocas.

Viene de Palenque.

Sus ojos verdes brillan; sus brazos son hermosos;

le sigue un astro, y se pierde.

Es el trópico.

La frente cac como un fruto

sobre la mano fina y estéril.

Y cl alma vucla.

Y en una línea nueva de la garza,

renace el tiempo,

lento, fecundo, ocioso,

creado para soñar y ser perfecto.

Publicado en IIora y 20(1927), es cl poema que da título al libro, con una frase de cxactitud irónica. Así como, cn otros poemas, Pcllicer usa la palabra cosa, que es la mismisima vaguedad, para decir algo muy exacto, aquí desprende de la 
fórmula "nueve y veinte", "diez y veinte", el primer número y lo sustituye por una vaguedad: hora. Es como si arrancara una de las manccillas del reloj para dejar únicamente el minutero. Convierte así la fórmula en una contradicción (la ridícula precisión de 20 frente a la vaguedad de hora) que es una imagen crítica (muy exacta) de la exactitud en la selva: de la exactitud fuera de lugar. Crítica del tren que no llega a una estación perdida cn la sclva. Crítica del telegrama. Crítica del rcloj ante la inmensa relojería vegetal: "máquinas gigantescas y translúcidas del silcncio".

El pocma está lleno de imágenes memorables. Hay dos que recucrdan gregucrías de Ramón Gómez de la Scrna:

El cocodrilo es un perro aplastado (Pellicer). El cocodrilo es un zapato desclavado (Gómez de la Serna).

La serpiente se suma veinte veces (Pcllicer). La serpiente mide el bosque para saber cuåntos metros tienc y decírsclo al ángel de las estadísticas (Gómez de la Scrna).

En el scgundo caso, llama la atención la coincidencia de la primera imagen (la serpiente como cinta métrica) y la extraordinaria diferencia del resultado final. Gómez de la Serna se queda en la primera imagen y la complica con despliegues explicativos. "La serpiente mide el bosque" dice lo que hay que decir. Pero, quizá inseguro de que sca suficiente, o quizá engolosinado con el descubrimiento, no se detiene ahí: añade que lo mide para saber cuántos metros tiene, ctc.

En cambio, la solución de Pellicer es vertiginosa. En vez de diluir su descubrimiento, lo intensifica, lo usa para decir algo más: una segunda imagen construida sobre la primera. Esta segunda imagen (la cinta métrica serpentea como si se midiera a sí misma) es de una perfección admirable para hacer ver una serpiente que va pasando junto a sí misma haciendo cses. Lo más admirable de todo es que las eses ni siquicra se mencionan explícitamente. En otro Estudio, Pellicer recurre a las eses para referirse a la cáscara de la naranja pclada con el cuchillo:

Salían de sus eses redondas las naranjas.

En éste, la mención no es necesaria: la imagen auditiva está llena de eses a travćs de la alitcración (ser, se, su, ces: pronunciada en México como ses) y de la palabra veces que suena a eses. La imagen auditiva serpentea a través de la alitcración silbantc. Casi cstamos oyendo cl silbido de la serpiente, cl ssssss de su paso. Y esto se refuerza con la imagen visual de serpenteo, y con el significado de se suma. Sumarse es repasarse, medirse contra si mismo, alcanzar la autosuficiencia que es principio y fin, tiempo que se muerde la cola. En la imagen de Gómez de la Scrna, la serpiente cstá al servicio de la estadística. En la de Pellicer, por el 
contrario, la serpiente es negación del tiempo lineal: es inconmesurable con la serpiente de "dicz kilómetros sobre la vía de un tren retrasado". En la serpiente que se suma veinte veces no hay " $\mathrm{y} 20$ " (aunque el número coincida); hay una hora que se reproduce vcinte veces: "de una salen dicz" (aunque el número no coincida). Y "Nadic sabe qué hora cs".

A manera de experimento, el lector puede inventar una serie de variantes. Por cjemplo:

La serpiente se suma siete veces.

La serpiente se suma en veinte eses.

La víbora se bebe veinte veces.

La víbora se vive veinte veces.

Sucnan bien. ¿Por qué no funcionan tan bien? Dígalo cl lector.

\section{DICTADURA Y MISTERIO}

\section{ESTUDIO}

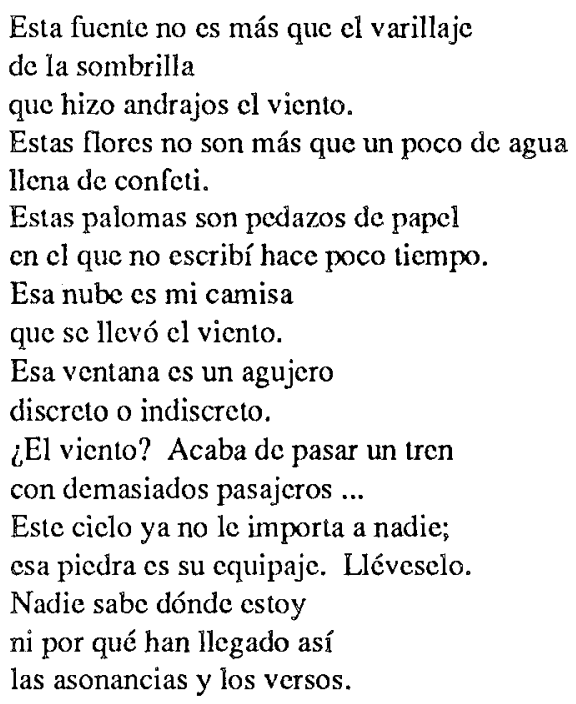

Aunque Pcllicer admiraba a Díaz Mirón, y escribió cientos de sonctos, no cs un pocta de pocmas redondos. La fragmentación e irregularidad de la vanguardia le sientan mejor que la redondez modernista, de la cual sin embargo tuvo nostalgia. 
Este cs uno de sus pocmas más redondos, y no es un soneto. Tiene $\mathrm{cl}$ desenvolvimiento, la fluencia, cl avance inexorable, consecuente, imaginativo, de un soneto perfecto. El final, que parcce un non sequitur, una forma cualquicra de crminar, es sin embargo la desembocadura natural del poema. Se trata de un pocma sobre la crcación poćtica. Casi un poema creacionista, si no fucra por la humildad de cse final: nadic sabe donde, ni por qué, llegan así los versos.

Ese corte aparente del tema aparente (la fuente, las flores) subray a cl verdadero tema (la creación). Es como si viéramos en cine una sombrilla que se vuclve una fucntc; y, al relirarse la cámara, vićramos una mano pintando esa transformación; y luego todavía al camarógrafo que filmó la mano.

Es una mano dictadora. Donde pone el dedo pone otra realidad. Da órdenes, desprecia, reduce. Las flores "no son más que"..., la fuente "no cs más que"... Pero el desdoblamiento (del camarógrafo: pintor que pinta la mano pintando), la ironía sobre cl aclo creador-dictador, lo lleva más allá de sus pretensiones mágicas y las rebasa: la mano hace milagros. Es como si el dictador le diera órdenes al sol de retirarse ... y oscurecicra.

Así, la realidad reducida remite a una realidad milagrosa en la mismísima reducción: cl milagro metafórico. Así invierte el sentido de la reducción. Despućs de una fiesta, queda confeti en un charco y nos parece basura: Pellicer ve un ramo de flores. Vemos una sombrilla que hace andrajos $\mathrm{el} \mathrm{viento} \mathrm{y} \mathrm{vemos} \mathrm{un} \mathrm{despojo:}$ Pellicer ve brotar una fuente. Vemos una piedra: Pellicer ve equipaje, viaje, ciclo.

El momento culminante de esta flexión del acto dictador-reductivo que lo muestra dictador-creador es una frase magistral, que consta de una sola palabra: "Lléveselo". Es una frase inusitada, que está en cl centro del pocma y lo divide en tres partes: primero, una serie de metáforas (A no es más que B; A cs B; ¿A? B); luego, esta frasc imperativa; por último, la afirmación final, que se opone a las dos partes antcriores y las cierra, como vimos.

Toda la gracia irónica del pocma estå en ese desplante dictador, en esa orden tcrminantc, que se opone a la scric de metáforas, al mismo tiempo que la continúa y la hace descmbocar en la humildad final. La scric avanza hacia este "Llévesclo", que rompe el molde de la seric con libertad suprema. En vez de hacer una comparación entre dos términos, cl poeta dictador da una orden que es una metáfora de otro tipo, una especie de colmo metafórico. La mano de Pellicer muestra la mano dictadora dando órdenes absurdas, con una gracia que rebasa al dictador y trasmuta la orden. Si la distinción de Austin puede aplicarse a las metáforas, pudiéramos decir que Pellicer pasa de las enunciativas a este caso rarísimo de metáfora cjecutiva.

La escena cambia tres veces por retiro del punto de vista (es decir: incluyendo y transformando la escena anterior). La primera es tan amplia que parece $\mathrm{cl}$ 
verdadcro tema, desde la fucnte hasia el equipaje: toda la scric de metáforas cnunciadas por un narrador que no aparece en escena hasta la escena dos, cuando aparece dando órdenes, como un autor pirandelliano frente a su obra (o como una mano pintada pintando). La escena tres recoge las escenas anteriores, al mostrar al pocta frente a tales escenas, que no sabe bien cómo escribió.

Todas las imágenes de la primera escena encajan en este posible escenario: una cstación de ferrocarril al aire libre, donde hay una fuente, palomas, restos de confeti, equipaje y un pocta absorto ante un ciclo espléndido, que ya no le importa a nadic, porque hay que irse: porque el tiempo del tren se impone al tiempo de la cternidad. En cstas circunstancias, hablar de piedras al cargar las malctas cs un lugar común, una metáfora ya hecha. También es una broma hecha la metáfora de bajar del ciclo o de las nubes al absorto, que no ve que se le va el tren. Así se cstablece la ccuación piedra $=$ cquipaje $=$ viaje $=$ cicio .

Hay una oposición de equivalencia entre piedra y ciclo (y no sólo en este caso: Jung la ha documentado en la cultura universal; aunque ninguno de sus cjemplos, muchos de los cuales tienen que ver con viaje, implican viaje con maleta, rasgo de humor pelliccriano). El ciclo es la ligereza, la vastedad, la libertad, cl espíritu. La piedra es el peso, la limitación, cl arraigo, la materia. El ciclo es viaje: la piedra cs negación del viajc. Pcro esta oposición resulta reconciliada con audacia y humor, al revirar dos burlas ordinarias. La frase hecha (estas malctas pesan como piedras) invertida se vuclve inédita (esta piedra es cquipaje). La burla consabida (bajar de las nubes) se vuelve de una ambigüedad entre derogativa y prometeica (cargar con cl cielo). La oposición piedra/ciclo se resuclve a través de otra oposición: viaje/viaje. Hay que dejar el viaje absorto, para emprender cl viaje en tren. Hay que lievarse el viajc absorto al tren. Hay que llevarse cl cicloen la maleta. Cargar con el cquipaje del ciclo. "Esa nube es mi camisa", arrastrada por la inspiración del viento.

Las ambigüedades gramaticales enriquecen la metáfora. ¿A qué se refiere "Llévesclo"? Puede ser "Este cielo" o pucde ser "su equipaje". ¿De quién es "su" equipaje? Pucde ser del ciclo o pucde ser de usted, a quien le digo "Llévesclo". ¿Cómo llevarse cl ciclo? En los ojos, sin duda alguna; pero tambićn como uransparencia reducida a carga, $\mathrm{cn}$ las manos del absorto que baja de las nubes y carga con las nubes almidonadas y petrificadas. ¿Quién le dice a quién "Llévesclo"? El pocta dictador al pocta absorto (ambos pintados por el pocta irónico, que sabe que la dictadura no es creadora, que la creación es un mistcrio que rcbasa la voluntad de creación, como decía nuestro padre Ayocuan: "del cicío vienen las bellas flores, los bellos cantos. Los afea nuestro anhelo, nuestra inventiva los ccha a perder"). Y ¿qué le dice, al decirle "Llévesclo"? Cargue con su éxtasis, que no le importa a nadic. 
El viaje absorto se convierte en piedra, por órdenes del poeta dictador. Pcro la realidad reducida y despreciada remite a una rcalidad milagrosa en la misma reducción. Las nubes se petrifican de verdad. La piedra resulta cielo, viaje, cquipajc: piedra filosofal que reconcilia opuestos: metáfora ejccutiva de una equivalencia que, en el mismo acto, cambia su sentido reductivo; milagro de ese "Llévesclo", que ni el pocta sabe como escribió, en otro viaje absorto, después del cual hay como un despertar en otra parte: "Nadie sabe dónde estoy".

Hay una humildad irónica en el poema. Humor sobre el misterio de la propia creación. El poeta (irónico sobre su propia hubris creacionista) le toma la palabra, la mano dictadora, al pocta "como un pequeño dios", $y$, con arte de judo (dejándolo seguir cl movimiento dictador hasta sus últimas consecuencias), hace que dé una voltcreta.

Redonda, milagrosamente, todo lo que no es más que ... se convierte en nada menos que... 